\title{
2D Layered Manganese Oxide Nanosheets as a Bifunctional Electrocatalyst for Zn- Air Batteries
}

\author{
Soracha Kosasang, ${ }^{\mathrm{a}, \mathrm{b}}$ Nattapol Ma, ${ }^{\mathrm{a}, \mathrm{b}}$ Praeploy Chomkhuntod, ${ }^{\mathrm{a}, \mathrm{b}}$ Chonticha Jangsan, ${ }^{\mathrm{a}, \mathrm{b}}$ \\ and Montree Sawangphruk ${ }^{\mathrm{a}, \mathrm{b}, *}$ \\ ${ }^{a}$ Department of Chemical and Biomolecular Engineering, School of Energy Science and \\ Engineering, Vidyasirimedhi Institute of Science and Technology, Rayong 21210, \\ Thailand. \\ ${ }^{\mathrm{b}}$ Centre of Excellence for Energy Storage Technology (CEST), Vidyasirimedhi Institute \\ of Science and Technology, Rayong 21210, Thailand.
}

In this work, we demonstrate layered manganese oxide with potassium intercalated cation (K-birnessite) as a bifunctional electrocatalyst for $\mathrm{Zn}$-air battery with an open circuit potential $(\mathrm{OCP})$ of $1.31 \mathrm{~V}$ versus $\mathrm{Zn} / \mathrm{Zn}^{2+}$. $\mathrm{Zn}$-air battery using K-birnessite catalyst exhibits a small potential gap between discharge and charge potential of $0.79 \mathrm{~V}$ measured via galvanostatic discharge-charge technique at a current density of $2 \mathrm{~mA} \mathrm{~cm}^{-2}$ in the ambient air with $2 \mathrm{hr}$ per cycle. Moreover, the cyclability of $\mathrm{Zn}$-air battery using Kbirnessite measured with a short period of 10 min per cycle exhibits cyclable stability over $10 \mathrm{hr}$ which is better than the Zn-air battery using the state-of-art mixed catalyst of $\mathrm{Pt} / \mathrm{C}$ and $\mathrm{RuO}_{2}(8 \mathrm{hr})$. This 2D layered $\mathrm{K}-\mathrm{MnO}_{2}$ may be practically used as a bifunctional catalyst in metal-air batteries.

\section{Introduction}

The exceeded $400 \mathrm{ppm}$ of carbon dioxide concentration in the atmosphere was initially recorded in 2015 which is a high concentration as compared to the past.(1) The carbon dioxide is mainly emitted from a production of energy and electricity by nonrenewable fossil fuels which is the main cause of air and water pollutant as well as a climate change.(2) Therefore, sustainable and green power sources with high energy or power density such as metal-air batteries and fuel cells have been attractive due to their sufficient theoretical energy density for electric vehicles $(\mathrm{EVs}) .(3,4)$

Zn-air battery is one of interesting energy storage devices due to their inexpensive cost, environmental friendliness, and safety which can generate energy via redox reaction between oxygen gas from the atmosphere at the air cathode and $\mathrm{Zn}$ metal at the anode.(5- 
9) Oxygen gas from the atmosphere diffuses through gas diffusion layer (GDL) and is reduced to form hydroxide anion $\left(\mathrm{OH}^{-} ; \mathrm{O}_{2}+\mathrm{H}_{2} \mathrm{O}+4 \mathrm{e}^{-} \rightarrow 4 \mathrm{OH}^{-}\right)$during discharge process which is known as oxygen reduction reaction (ORR)(9-11), while $\mathrm{Zn}$ metal at the anode is oxidized to form $\mathrm{Zn}^{2+}\left(\mathrm{Zn} \rightarrow \mathrm{Zn}^{2+}+2 \mathrm{e}^{-}\right)$and then reacted with $\mathrm{OH}^{-}$to generate zincate intermediate $\left(\mathrm{Zn}(\mathrm{OH})_{4}{ }^{2-} ; \mathrm{Zn}^{2+}+4 \mathrm{OH}^{-} \rightarrow \mathrm{Zn}(\mathrm{OH})_{4}{ }^{2-}\right) .(4,12,13)$ The zincate species is then transformed to zinc oxide $(\mathrm{ZnO})$ and regenerated $\mathrm{H}_{2} \mathrm{O}$ and $\mathrm{OH}^{-}\left(\mathrm{Zn}(\mathrm{OH})_{4}{ }^{2-} \rightarrow \mathrm{ZnO}+\mathrm{H}_{2} \mathrm{O}\right.$ $\left.+2 \mathrm{OH}^{-}\right) \cdot(4,12,13)$ During the charging process, $\mathrm{OH}^{-}$is oxidized to regenerated oxygen gas $\left(4 \mathrm{OH}^{-} \rightarrow \mathrm{O}_{2}+2 \mathrm{H}_{2} \mathrm{O}+4 \mathrm{e}^{-}\right)$which is known as oxygen evolution reaction (OER)(11, 14). Therefore, the overall reaction of $\mathrm{Zn}$-air battery is $2 \mathrm{Zn}+\mathrm{O}_{2} \rightarrow 2 \mathrm{ZnO}\left(\mathrm{E}^{\mathrm{o}}=+1.65 \mathrm{~V}\right.$ versus $\left.\mathrm{Zn} / \mathrm{Zn}^{2+}\right) .(4,12,13)$ Although metal-air batteries are a promising energy storage device, the sluggish kinetics of the ORR and OER is a major challenge of this battery which limits their practical applications.(15-18) Hence, bifunctional electrocatalyst is the key factor to accelerate the rate of these reactions. $(11,14,19)$ Platinum has been recognized as the superior catalyst for the ORR and ruthenium and iridium-based catalyst have been suggested as high-performance catalysts for the OER, however, expensive cost and low stability of these materials suppress their practical utilization.(20-24) Manganese-based material is one of attractive candidates in alkaline-based electrolyte due to their natural abundance and low toxicity.(25) Additional advantages of manganese oxides are their polymorphs such as $\alpha-\mathrm{MnO}_{2}, \beta-\mathrm{MnO}_{2}, \gamma-\mathrm{MnO}_{2}$, and $\delta-\mathrm{MnO}_{2}$ as well as multi valence states.(25-31) $\delta-\mathrm{MnO}_{2}$ or birnessite-type layered manganese oxide, the 2D layers of edgesharing manganese octahedra $\left(\mathrm{MnO}_{6}\right)$ with cations and/or water molecules intercalated within $\mathrm{MnO}_{2}$ layer, is an attractive structure because the valence states of the birnessite contain $\mathrm{Mn}^{(\mathrm{III})}$ and $\mathrm{Mn}^{(\mathrm{IV})}$ leading to a high catalytic activities and the structure is tunable of intercalated cations between $\mathrm{MnO}_{2}$ layers.(15, 32, 33)

Here, we demonstrate Zn-air battery using K-birnessite as a bifunctional electrocatalyst with an open circuit potential (OCP) of $1.31 \mathrm{~V}$ versus $\mathrm{Zn} / \mathrm{Zn}^{2+}$. $\mathrm{Zn}$-air battery using K-birnessite exhibits a small potential gap between discharge and charge potential of $0.79 \mathrm{~V}$ along with high cyclability than the state-of-art mixed catalyst of $\mathrm{Pt} / \mathrm{C}$ and $\mathrm{RuO}_{2}$.

\section{Experimental}

\section{$\underline{\text { Chemicals and materials }}$}

Manganese (II) nitrate tetrahydrate $\left(\mathrm{Mn}\left(\mathrm{NO}_{3}\right)_{2} \cdot 4 \mathrm{H}_{2} \mathrm{O}, 98 \%\right.$, Loba Chemie), potassium hydroxide $\left(\mathrm{KOH}\right.$, Ajax Finechem), zinc acetate $\left(\left(\mathrm{CH}_{3} \mathrm{CO}_{2}\right)_{2} \mathrm{Zn}, 99.99 \%\right.$, Merck), hydrogen peroxide $\left(\mathrm{H}_{2} \mathrm{O}_{2}, 30 \%\right.$, Chem-supply), N-Methyl-2-pyrrolidone (NMP, 99.5\%, Qrec), Polyvinylidene fluoride (PVDF, Mw 534,000, Aldrich), and carbon black (TIMCAL) are analytical grade. $\mathrm{Ni}$ foam is used as a substrate(34) and carbon fiber paper(35) (CFP, SGL Carbon SE in Germany) is used as a gas diffusion layer for Zn-air battery. Glass microfiber filters (Whatman, GF/F) was used as a separator. Deionized water is purified using Milli-Q system (DI water, $15 \mathrm{M} \Omega \cdot \mathrm{cm}$, Millipore). 


\section{Synthesis of K-birnessite}

K-birnessite was synthesized by slowly adding $100 \mathrm{~mL}$ of $0.6 \mathrm{M} \mathrm{KOH}$ and $1 \mathrm{M}$ $\mathrm{H}_{2} \mathrm{O}_{2}$ solution into $60 \mathrm{~mL}$ of $0.25 \mathrm{M} \mathrm{Mn}\left(\mathrm{NO}_{3}\right)_{2} \cdot 4 \mathrm{H}_{2} \mathrm{O}$ solution with stirring at room temperature. The black-brown suspension was observed, then aged the suspension for $2 \mathrm{hr}$. The obtained product was washed with DI water using filtration technique and dried at room temperature $\left(25^{\circ} \mathrm{C}\right) .(15)$

\section{$\underline{\text { Morphological and structural characterizations }}$}

Field emission scanning electron microscopy (FE-SEM, JSM-7001F, JEOL Ltd.) was applied to observe morphology of sample. Powder x-ray diffraction (PXRD, Bruker D8 ADVANCE) using $\mathrm{Cu} \mathrm{K} \alpha$ radiation $\left(30 \mathrm{kV}, 40 \mathrm{~mA}\right.$ ) with a step size of $0.01^{\circ}$ in the $2 \theta$ range of $5-80^{\circ}$ was performed to identify crystallographic structure of material. Chemical structure was characterized by Raman spectroscopy (Senterra Dispersive Raman, Bruker Optics, Germany, operated at a laser wavelength of $532 \mathrm{~nm}$ ). Ultraviolet photoelectron spectrometer (UPS, RIKEN KEIKI, AC-2, U.S.A.) and UV-Visible-Near IR spectrometer (UV/Vis/NIR Lambda 1050, PerkinElmer, U.S.A.) were applied to investigate the electronic property of materials.

\section{$\underline{\text { Fabrication of } \mathrm{Zn} \text {-air batteries }}$}

$\mathrm{Zn}$-air batteries consist of zinc metal as an anode, a glass microfiber filter as a separator, and an air electrode compressed in $6 \mathrm{M} \mathrm{KOH}$ electrolyte containing $0.2 \mathrm{M}$ zinc acetate. Catalyst ink was prepared by mixing $20 \mathrm{mg}$ of catalyst and $20 \mathrm{mg}$ of carbon black (Super P) in $200 \mu \mathrm{L}$ of $5 \%$ PVDF in NMP solution and $400 \mu \mathrm{L}$ of NMP. Then, the mixture was sonicated for 2 hours. Air electrode was prepared by coating catalyst ink on nickel foam substrate $\left(2.5 \mathrm{mg} \mathrm{cm}^{-2}\right)$. Zn-air cells were fabricated by hydraulic press machine at 2000 psi.

\section{Results and Discussion}

\section{$\underline{\text { Physicochemical characterization }}$}

Figure 1a shows a scanning electron microscope (SEM) image of layered manganese oxide with potassium intercalated cation (K-birnessite) which demonstrates a sheet-like structure. Transmission electron microscope (TEM) image exhibits d-spacing of $0.7 \mathrm{~nm}$ corresponding to an interlayer spacing between (001) plane of the birnessite structure. $(11,15,36,37)$ 


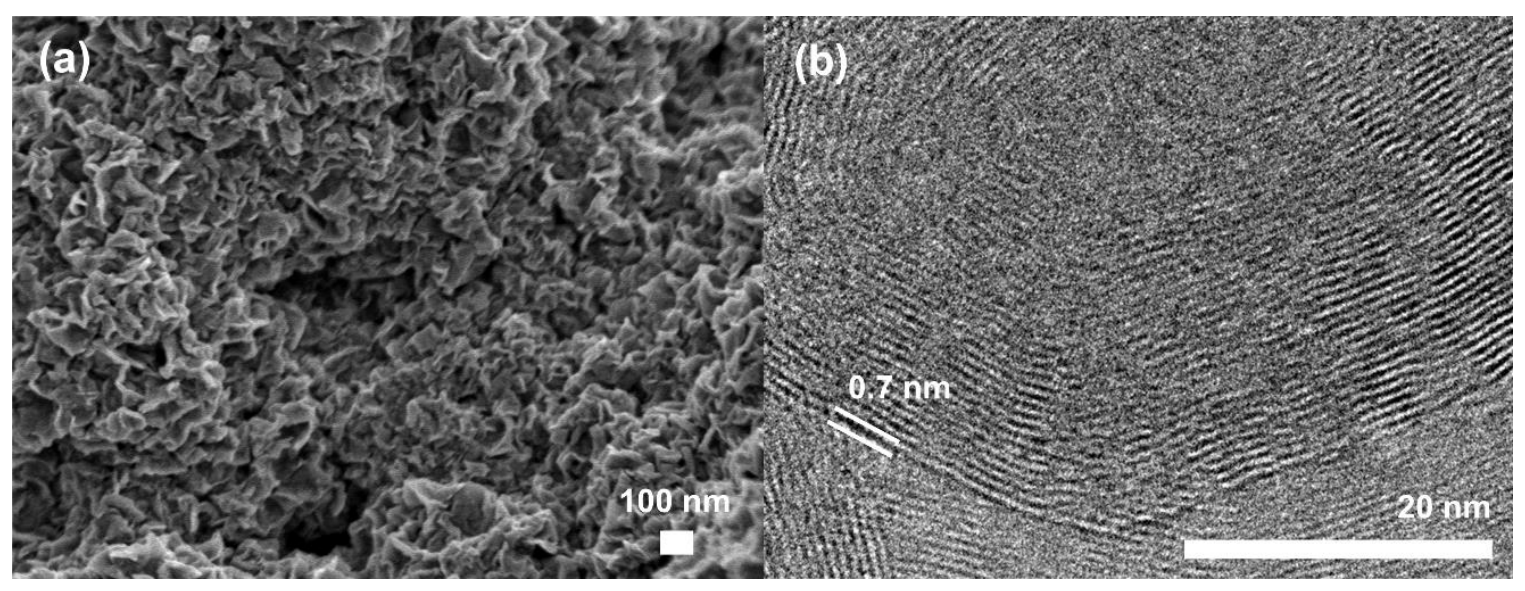

Figure 1. (a) SEM image of K-birnessite and (b) TEM image of K-birnessite.

Furthermore, XRD pattern displays peaks at two-theta around $11.8^{\circ}, 25.0^{\circ}, 36.5^{\circ}$, and $64.8^{\circ}$ which can be assigned to (001), (002), (-111), and (020) plane of the birnessite structure, respectively (figure 2a).(15) The interlayer spacing between layers of the Kbirnessite can be calculated via Bragg's law (eq. 1) which is equivalent to ca. $0.73 \mathrm{~nm}$ with a good agreement with TEM result. In addition, Raman spectrum of K-birnessite shows three major vibration peaks at $635.5,578.0$, and $512.0 \mathrm{~cm}^{-1}$ which the vibration peak at 635 $\mathrm{cm}^{-1}$ and $578.0 \mathrm{~cm}^{-1}$ can be assigned to the symmetric $\mathrm{Mn}-\mathrm{O}$ vibration of $\mathrm{MnO}_{6}$ group and $\mathrm{Mn}-\mathrm{O}$ basal plane stretching, respectively (figure $2 \mathrm{~b}$ ).(38)

$$
\mathrm{n} \lambda=2 \mathrm{~d} \sin \theta
$$

where,

$\mathrm{d}$ is a spacing between layers of atoms

$\theta$ is an angle between an incident $\mathrm{x}$-ray and a surface of crystalline sample

$\mathrm{n}$ is an integer, the order of reflection

$\lambda$ is an X-ray wavelength. 

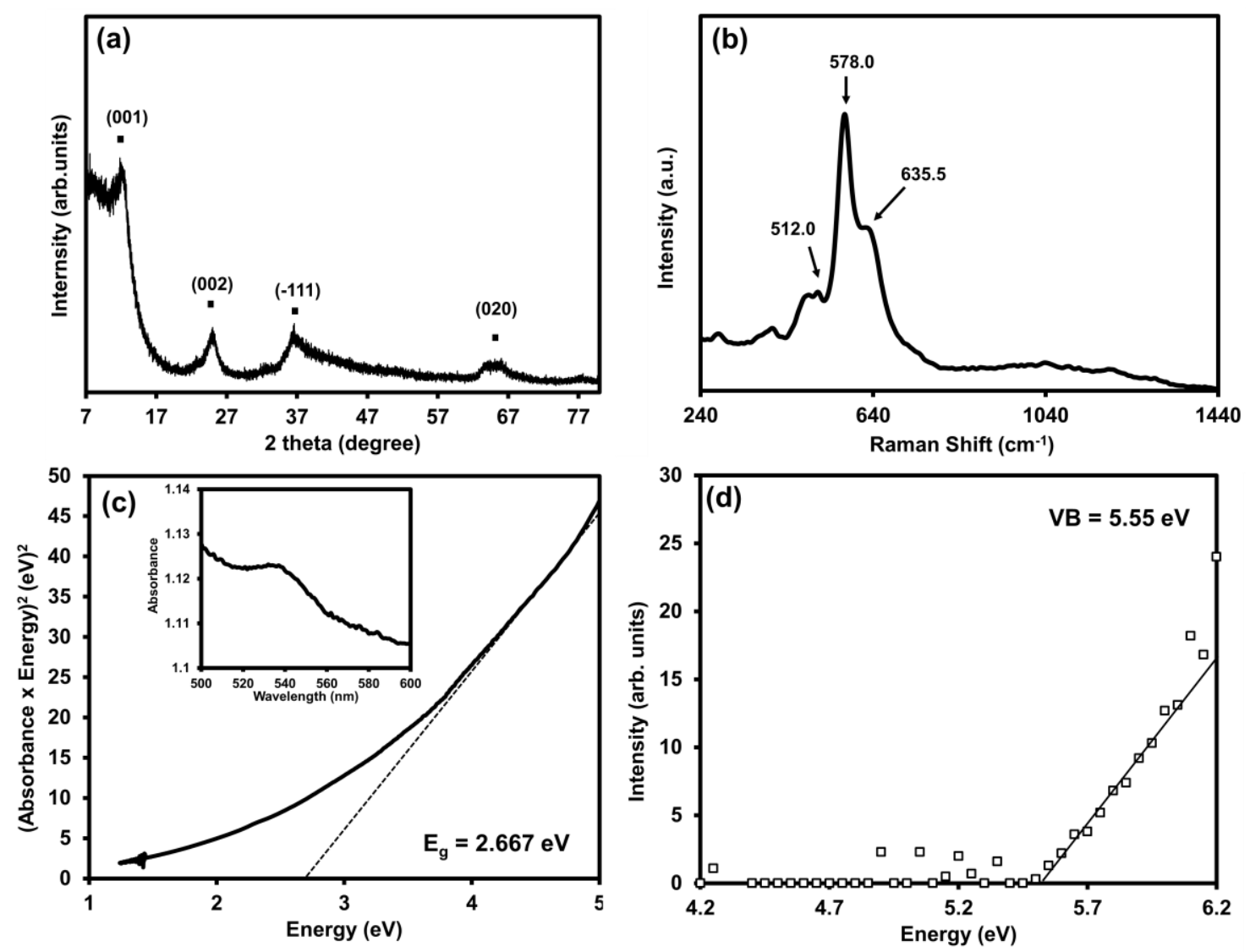

Figure 2. (a) XRD pattern of K-birnessite, (b) Raman spectrum of K-birnessite, (c) band gap energy of K-birnessite calculated from UV-VIS spectrum (inset), and (d) valence band energy of K-birnessite observed from the UPS technique.

To further demonstrate the electronic property, band gap energy along with valence band and conduction band energy of K-birnessite were identified via UV-VIS spectroscopy (UV-VIS) and ultraviolet photoelectron spectroscopy (UPS), respectively (figure 2c-d). UV-VIS spectrum shows the adsorption peak at ca. $540 \mathrm{~nm}$ which can be further calculated to a band gap energy via equation 2.(39) Band gap energy of $\mathrm{K}$ - birnessite is equivalent to $2.667 \mathrm{eV}$ along with valence band energy observed from the UPS technique of K-birnessite which is equivalent to $5.55 \mathrm{eV}$. Consequently, the conduction band energy of K-birnessite is $2.883 \mathrm{eV}$.

$$
(\alpha \mathrm{h} v)^{2}=\alpha_{\mathrm{o}}\left(\mathrm{h} v-\mathrm{E}_{\mathrm{g}}\right)
$$

where,

$\alpha$ is an absorption coefficient

$\mathrm{h} v$ is an incident photon energy

$\alpha_{\mathrm{o}}$ is a band tailing parameter

$E_{g}$ is sn optical energy gap 


\section{$\underline{\text { Zn-air batteries }}$}

Zn-air batteries were fabricated and tested via galvanostatic discharge-charge technique at a current density of $2 \mathrm{~mA} \mathrm{~cm}^{-2}$ in the ambient air. Figure $3 \mathrm{a}$ shows an open circuit potential (OCP) of $1.31 \mathrm{~V}$ versus $\mathrm{Zn} / \mathrm{Zn}^{2+}$ of $\mathrm{Zn}$-air battery using K-bir. Figure $3 \mathrm{~b}$ shows discharge-charge profile of $\mathrm{Zn}$-air batteries using $\mathrm{K}$-bir and $\mathrm{Pt} / \mathrm{C}+\mathrm{RuO}_{2}$ as bifunctional electrocatalysts during cycling at a current density of $2 \mathrm{~mA} \mathrm{~cm}^{-2}$ with a long period of $2 \mathrm{hr}$ per cycle. Zn-air battery using K-bir exhibits a higher potential gap between discharge and charge potential of $0.79 \mathrm{~V}$ as compared to $\mathrm{Zn}$-air battery using $\mathrm{Pt} / \mathrm{C}+\mathrm{RuO}_{2}$ $(0.67 \mathrm{~V})$. However, a potential gap of $\mathrm{Zn}$-air battery using $\mathrm{Pt} / \mathrm{C}+\mathrm{RuO}_{2}$ is higher up to 0.77 $\mathrm{V}$ during the third cycle, while a potential gap of $0.79 \mathrm{~V}$ of $\mathrm{Zn}$-air battery using K-bir still maintains. Moreover, the stability of $\mathrm{Zn}$-air batteries was also evaluated via galvanostatic discharge and charge at a current density of $2 \mathrm{~mA} \mathrm{~cm}^{-2}$ with a short period of $10 \mathrm{~min}$ per cycle in ambient air. The stability of the Zn-air battery using K-bir can be cycled over 10 hours while the $\mathrm{Zn}$-air battery with the $\mathrm{Pt} / \mathrm{C}+\mathrm{RuO} 2$ can be cycled only 8 hours which can confirm a better cyclability of the Zn-air battery using K-bir.
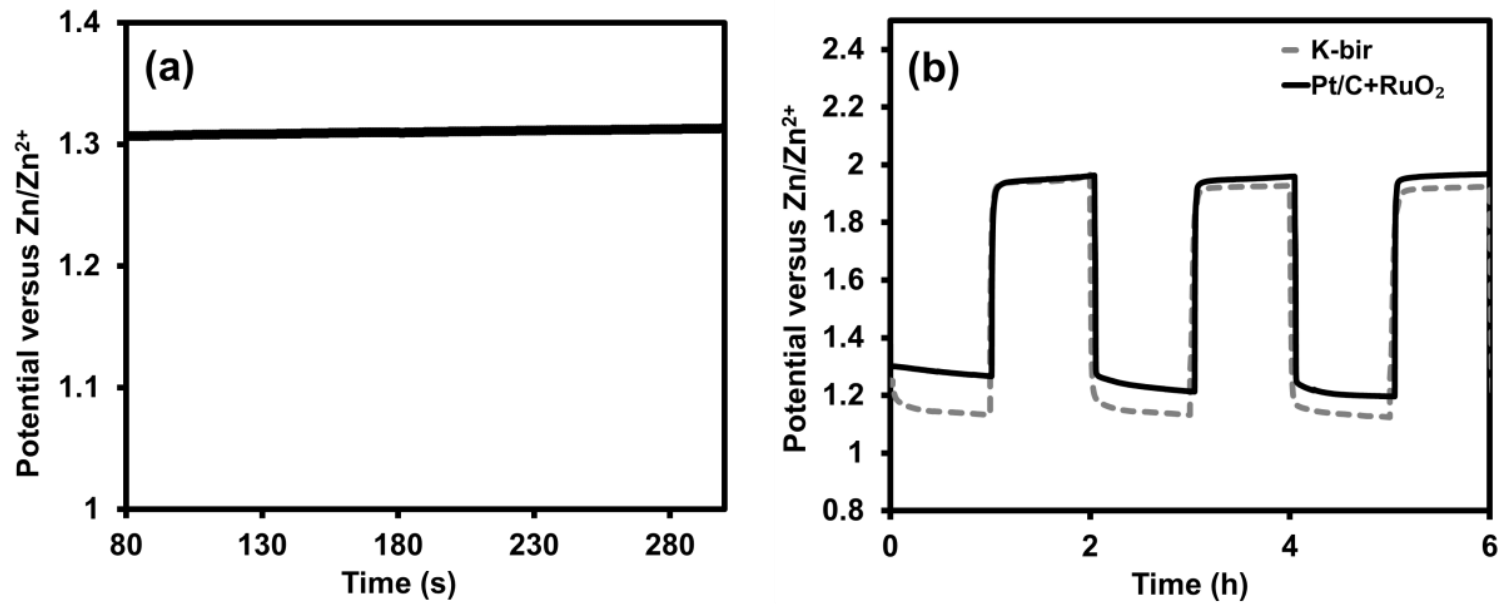

Figure 3. (a) OCP of Zn-air battery using K-bir and (b) galvanostatic discharge and charge profile of $\mathrm{Zn}$-air batteries using K-bir and a mixture of $\mathrm{Pt} / \mathrm{C}$ and $\mathrm{RuO}_{2}$ at a current density of $2 \mathrm{~mA} \mathrm{~cm}^{-2}$ with 2 hours per cycle.

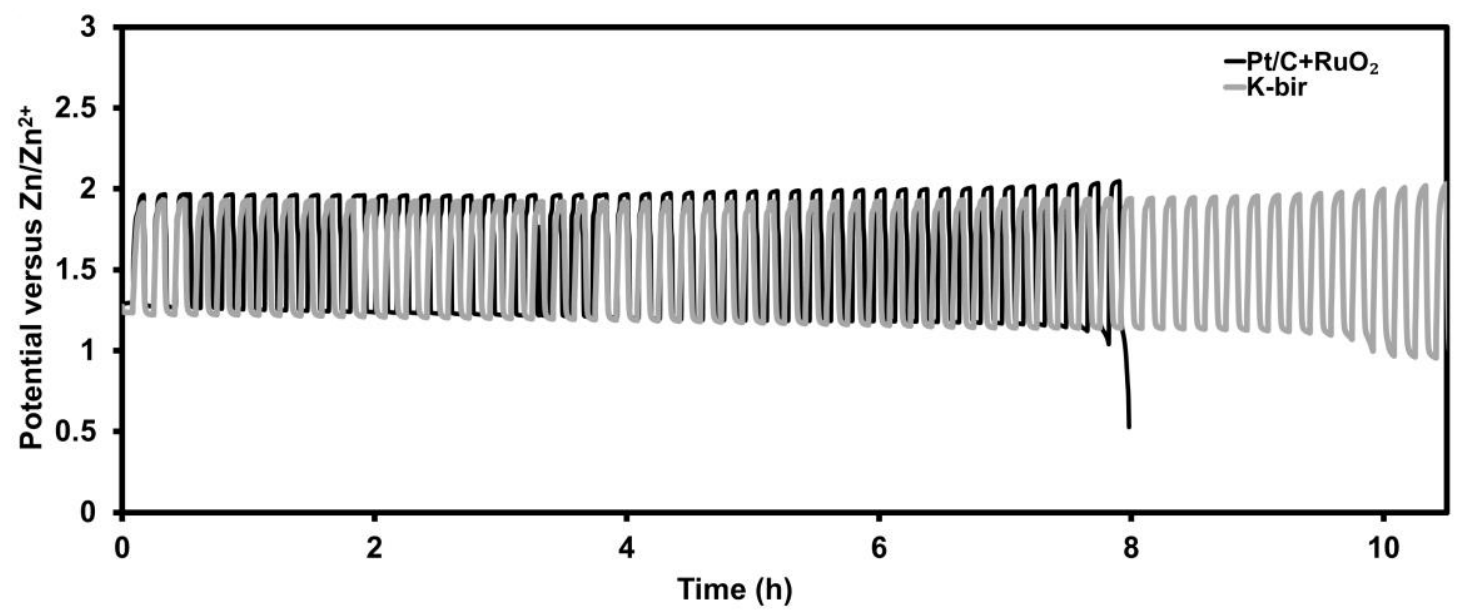


Figure 4. Stability of the $\mathrm{Zn}$-air batteries using the $\mathrm{K}$-bir and the mixture of $\mathrm{Pt} / \mathrm{C}$ and $\mathrm{RuO}_{2}$ during cycling at a current density of $2 \mathrm{~mA} \mathrm{~cm}^{-2}$ with 10 minutes per cycle in ambient air.

\section{Conclusion}

In this work, we demonstrate K-birnessite $\mathrm{MnO}_{2}$ as a bifunctional electrocatalyst for $\mathrm{Zn}$-air battery. The $\mathrm{Zn}$-air battery using K-birnessite exhibits an open circuit potential of $1.31 \mathrm{~V}$ vs. $\mathrm{Zn} / \mathrm{Zn}^{2+}$. Although $\mathrm{Zn}$-air battery using K-birnessite shows a higher potential gap between discharge and charge potential $(0.79 \mathrm{~V})$ than $\mathrm{Zn}$-air battery using the state-ofart mixed catalyst of $\mathrm{Pt} / \mathrm{C}$ and $\mathrm{RuO}_{2}(0.67 \mathrm{~V})$ during the first cycle, $\mathrm{Zn}$-air battery using $\mathrm{K}$ birnessite can maintain the potential gap at the third cycle, while $\mathrm{Pt} / \mathrm{C}+\mathrm{RuO}_{2}$ has a significantly higher potential gap. Additionally, the $\mathrm{Zn}$-air battery using our catalyst can be cycled over $10 \mathrm{hr}$ suggesting the better stability of our catalyst than the $\mathrm{Pt} / \mathrm{C}+\mathrm{RuO}_{2}$ which can be cycled only $8 \mathrm{hr}$. This $\mathrm{K}-\mathrm{MnO}_{2}$ bifunctional catalyst may be practically used in metal-air batteries.

\section{Acknowledgments}

This work was financially supported by the Thailand Research Fund and Vidyasirimedhi Institute of Science and Technology (RSA6180031 and RTA6080005) as well as Energy Policy and Planning Office (EPPO), Ministry of Energy, Thailand.

\section{References}

1. J. K. Stolarczyk, S. Bhattacharyya, L. Polavarapu and J. Feldmann, ACS Catal., 8, $3602(2018)$.

2. J. Ran, M. Jaroniec and S.-Z. Qiao, Adv. Mater., 30, 1704649 (2018).

3. L. Kuai, E. Kan, W. Cao, M. Huttula, S. Ollikkala, T. Ahopelto, A.-P. Honkanen, S. Huotari, W. Wang and B. Geng, Nano Energy, 43, 81 (2018).

4. J. Pan, Y. Y. Xu, H. Yang, Z. Dong, H. Liu and B. Y. Xia, Adv. Sci., 5, 1700691 (2018).

5. P. Jing, X. Y. Yang, Y. Huan, D. Zehua, L. Hongfang and X. B. Yu, Adv. Sci., 5, 1700691 (2018).

6. S. Liu, M. Wang, X. Sun, N. Xu, J. Liu, Y. Wang, T. Qian and C. Yan, Adv. Mater., 30, 1704898 (2018).

7. B.-Q. Li, S.-Y. Zhang, B. Wang, Z.-J. Xia, C. Tang and Q. Zhang, Energy Environ. Sci., 11, 1723 (2018).

8. C. Hui, L. Mei-Ling, S. Chang-Yuan, L. Nan and L. Zhao-Qing, Adv. Funct. Mater., 27, 1701833 (2017).

9. J. S. M. Lee, S. Sarawutanukul, M. Sawangphruk and S. Horike, ACS Sustain. Chem. Eng., 7, 4030 (2019). 
10. S. Kosasang, N. Ma, N. Phattharasupakun, J. Wutthiprom, J. Limtrakul and M. Sawangphruk, ECS Trans. 85, 1265 (2018).

11. S. Kosasang, N. Ma, P. Wuamprakhon, N. Phattharasupakun, T. Maihom, J. Limtrakul and M. Sawangphruk, Chem. Commun., 54, 8575 (2018).

12. X. Cai, L. Lai, J. Lin and Z. Shen, Mater. Horiz., 4, 945 (2017).

13. J.-S. Lee, S. Tai Kim, R. Cao, N.-S. Choi, M. Liu, K. T. Lee and J. Cho, Adv. Energy Mater., 1, 34 (2011).

14. H. Gatemala, S. Kosasang and M. Sawangphruk, Sust. Energy Fuels, 2, 1170 (2018).

15. S. Kosasang, N. Ma, P. Wuamprakhon, N. Phattharasupakun, T. Maihom, J. Limtrakul and M. Sawangphruk, Chem. Commun., 54, 8575 (2018).

16. H. Gatemala, S. Kosasang and M. Sawangphruk, Sustain. Ener, 2, 1170 (2018).

17. L. Qin, W. Yaobing, D. Liming and Y. Jiannian, Adv. Mater., 28, 3000 (2016).

18. L. Yang, L. Shi, D. Wang, Y. Lv and D. Cao, Nano Energy, 50, 691 (2018).

19. W. Niu, S. Pakhira, K. Marcus, Z. Li, J. L. Mendoza-Cortes and Y. Yang, Adv. Ener. Mater., 8, 1800480 (2018).

20. F. Song and X. Hu, J. Am. Chem. Soc., 136, 16481 (2014).

21. J. Xu, P. Gu, D. J. S. Birch and Y. Chen, Adv. Funct. Mater., 28, 1801573 (2018).

22. S. Peng, X. Han, L. Li, S. Chou, D. Ji, H. Huang, Y. Du, J. Liu and S. Ramakrishna, Adv. Energy Mater., 8, 1800612 (2018).

23. Y. Jiang, Y.-P. Deng, J. Fu, D. U. Lee, R. Liang, Z. P. Cano, Y. Liu, Z. Bai, S. Hwang, L. Yang, D. Su, W. Chu and Z. Chen, Adv. Ener. Mater., 8, 1702900 (2018).

24. S. Luanwuthi, A. Krittayavathananon, P. Srimuk and M. Sawangphruk, Rsc Adv., 5, 46617 (2015).

25. Y. Meng, W. Song, H. Huang, Z. Ren, S.-Y. Chen and S. L. Suib, J. Am. Chem. Soc., 136, 11452 (2014).

26. Y. Xue, S. Sun, Q. Wang, Z. Dong and Z. Liu, J. Mater. Chem. A, 6, 10595 (2018).

27. Q. Tang, L. Jiang, J. Liu, S. Wang and G. Sun, ACS Catal., 4, 457 (2014).

28. M. Sawangphruk, S. Pinitsoontorn and J. Limtrakul, J. Solid State Electrochem., 16, 2623 (2012).

29. M. Sawangphruk and J. Limtrakul, Mater. Lett., 68, 230 (2012).

30. P. Iamprasertkun, A. Krittayavathananon, A. Seubsai, N. Chanlek, P. Kidkhunthod, W. Sangthong, S. Maensiri, R. Yimnirun, S. Nilmoung, P. Pannopard, S. Ittisanronnachai, K. Kongpatpanich, J. Limtrakul and M. Sawangphruk, Sci. Rep., 6, 12 (2016).

31. N. Phattharasupakun, J. Wutthiprom, N. Ma, P. Suktha and M. Sawangphruk, J. Electrochem. Soc., 165, A1430 (2018).

32. N. Ma, S. Kosasang, A. Krittayavathananon, N. Phattharasupakun, S. Sethuraman and M. Sawangphruk, Chem. Commun. (2018).

33. C. Tanggarnjanavalukul, N. Phattharasupakun, K. Kongpatpanich and M. Sawangphruk, Nanoscale, 9, 13630 (2017).

34. S. Sarawutanukul, N. Phattharasupakun, J. Wutthiprom and M. Sawangphruk, ECS Trans., 85, 49 (2018).

35. T. Maihom, S. Kaewruang, N. Phattharasupakun, P. Chiochan, J. Limtrakul and M. Sawangphruk, J. Phys. Chem. C, 122, 7033 (2018).

36. C. Tanggarnjanavalukul, N. Phattharasupakun, J. Wutthiprom, P. Kidkhunthod and M. Sawangphruk, Electrochim. Acta, 273, 17 (2018).

37. N. Ma, S. Kosasang, A. Krittayavathananon, N. Phattharasupakun, S. Sethuraman and M. Sawangphruk, Chem. Commun., 55, 1213 (2019). 
38. Y.-K. Hsu, Y.-C. Chen, Y.-G. Lin, L.-C. Chen and K.-H. Chen, J. Mater. Chem., 22, 2733 (2012).

39. A. S. Hassanien and A. A. Akl, Superlattice. Microst., 89, 153 (2016). 